\title{
Algunas reflexiones a propósito de la orden de detención de la Corte Suprema chilena contra Omar Al Bashir
}

Este comentario, junto a los documentos que analiza, está disponible en www.anuariocdh.uchile.cl

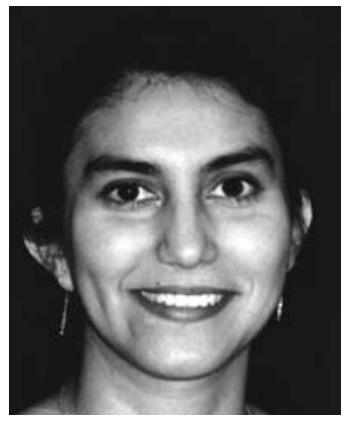

\section{Claudia Cárdenas Aravena}

Licenciada en Ciencias Jurídicas y Sociales de la Universidad de Chile (1999), Magíster y Doctora en Derecho por la Universidad Humboldt de Berlín (2001 y 2005 respectivamente). Autora de varias publicaciones, sobre todo en el ámbito del Derecho Penal Internacional. Profesora del Departamento de Ciencias Penales de la Facultad de Derecho de la Universidad de Chile. Actualmente está adscrita al programa de Doctorado de la misma casa de estudios. ccardenas@derecho.uchile.cl

\section{RESUMEN}

El artículo pone de relieve el fundamental rol que desempeña la cooperación estatal en el funcionamiento de la Corte Penal Internacional; reseña el caso seguido en contra de Omar Al Bashir y su relevancia, la cooperación que se solicitó para la detención y entrega de Omar Al Bashir al Estado chileno y la reacción ante dicha solicitud de cooperación. Contiene, asimismo, una valoración de dicha reacción desde la perspectiva del cumplimiento oportuno y de buena fe, de las obligaciones internacionales que, en ejercicio de su soberanía, ha adquirido el Estado de Chile. Finaliza con una prospectiva que destaca lo imprescindible de cumplir con la obligación internacional de adecuar la legislación interna, específicamente legislando sobre la cooperación del Estado chileno con la Corte Penal Internacional en los términos previstos en la parte IX de su Estatuto.

\section{Introducción: la Corte Penal Internacional como institución dependiente de la cooperación estatal}

La Corte Penal Internacional funciona desde el año 2003 y a la fecha (marzo de 2011) ha abierto investigaciones respecto de seis situaciones: Uganda, la República Democrática del Congo, la República Centroafricana, Darfur (Sudán), Kenia y Libia. No se conoce que existan personas imputadas respecto de Libia ${ }^{1}$. Sí las hay relativas a las situaciones en la República Democrática del Congo, Uganda, la República Centroafricana, Darfur (Sudán) y Kenia. Respecto de todas ellas son conocidas, en total, nueve órdenes de comparecencia ${ }^{2}$ y 15 órdenes

Puede haber órdenes de arresto que no sean de conocimiento público ("issued under seal").

2 Se ordenó comparecer a Bahar Idris Abu Garda, respecto de quien no se confirmaron los cargos, a Abdallah Banda Abakaer Nourain y a Saleh Mohammed Jerbo Jamas. Todos ellos fueron relacionados con la situación en Darfur. Además, recientemente se dictaron órdenes de comparecencia contra seis personas a quienes se les imputan crímenes de lesa humanidad relativos a la situación en Kenia. De ellas, tres (William Samoei Ruto, Henry Kiprono Kosgey y Joshua Arap Sang) han comparecido ante la Corte. Las otras tres personas (Francis Kirimi Muthaura, Uhuru Muigai Kenyatta y Mohammed Hussein Ali) no lo han hecho. 
de detención ${ }^{3}$. La gran mayoría (nueve) de los destinatarios de estas últimas no han comparecido ante el tribunal por no haber sido habidos. Uno de ellos habría muerto en el intertanto ${ }^{4}$.

Este indicador -número de órdenes de detención conocidas versus número de imputados que han comparecido ante el tribunal- basta para mostrar la dramática relevancia que tiene la cooperación de los Estados para que la Corte Penal Internacional pueda Ilevar adelante adecuadamente su quehacer. Como sus agentes no están facultados para detener a los imputados respecto de los cuales existen órdenes de detención, la Corte depende, para la ejecución de estas órdenes, de la cooperación de éstos.

El hecho de que la Corte dependa para su funcionamiento de la cooperación, principalmente estatal, lejos de ser un sorpresivo bache respecto de lo que se pensaba sería su quehacer, fue previsto por los negociadores del Estatuto de la Corte Penal Internacional. Precisamente por este motivo, dedicaron una parte completa del Estatuto -la parte IX-a la cooperación internacional y la asistencia judicial, dentro de la cual establecieron las obligaciones de cooperación para los Estados Partes. Por lo mismo, no es de extrañar que la campaña para obtener ratificaciones siga siendo particularmente relevante para la Corte, pues si bien el Estatuto de la Corte Penal Internacional cuenta ya con 114 Estados Partes -número relevante para cualquier tratado- todos los territorios de Estados no partes pueden servir de refugio para los imputados o para sus bienes.

Por otra parte, como ha sido destacado por la doctrina ${ }^{5}$, el régimen de cooperación previsto en el Estatuto de la Corte Penal Internacional no sólo condiciona la viabilidad de sus procesos, sino también, y en caso de concretarse la cooperación requerida, dota de legitimidad al actuar del tribunal. Éste no puede actuar si no es con el concierto de los Estados, que no cooperarían si no concibieran su actuar como legítimo. Esta es en gran medida la explicación de por qué la Corte Penal Internacional suele considerarse una organización internacional ${ }^{6}$ y no supranacional.

\section{Obligación estatal de cooperar}

La regla general es que los Estados Partes del Estatuto de la Corte Penal Internacional tienen obligación de cooperar con ella. El artículo 86 del Estatuto prevé la obligación general de los Estados Partes de cooperar, y en los artículos siguientes se especifican algunas obligaciones. Entre éstas resaltan la del artículo 88, de prever, en el derecho interno de cada Estado, procedimientos para cada una de las formas de cooperación que se especifican en la parte IX ${ }^{7}$, y la del artículo 97, de

3 Respecto de la situación en la República Democrática del Congo se conocen cinco órdenes de detención, en contra de las siguientes personas: Thomas Lubanga Dyilo, Bosco Ntaganda, Germain Katanga, Mathieu Ngudjolo Chui y Callixte Mbarushimana. Entre ellos, Bosco Ntaganda está prófugo; los demás han comparecido ante la Corte y se sigue un procedimiento en su contra. Respecto de la situación en Uganda se conocen cinco ordenes de detención: contra Joseph Kony, contra Vincent Otti, contra Okot Odhiambo y contra Dominic Ongwen (todos se encuentran prófugos), además de la orden contra Raska Lukwiya, quien habría fallecido sin ser detenido. Respecto de la situación en la República Centroafricana se ha conocido una orden de detención y entrega, contra Jean-Pierre Bemba Gombo, contra quien se está siguiendo un juicio. Respecto de la situación en Darfur (Sudán) se conocen cuatro órdenes de detención: una en contra de Ahmad Muhammad Harun ("Ahmad Harun"), otra en contra de Ali Muhammad Ali Abd-Al-Rahman ("Ali Kushayb"),y dos en contra de Omar Hassan Ahmad Al Bashir. Todos ellos se encuentran prófugos.

4 Se trata de Raska Lukwiya, en la Situación de Uganda.

5 MEISSNER, Jörg. Die Zusammenarbeit mit dem Internationalen Strafrerichtshof nach dem Römischen Statut. Munich, Verlag H. C. Beck, 2003, p. 5 y s.

6 Los Estados habrían creado este tribunal para investigar y juzgar, en conjunto, los crímenes más graves contra el derecho internacional, sin perder sus prerrogativas individuales al respecto. Cfr. MEISSNER, Jörg. Die Zusammenarbeit mit dem Internationalen Strafrerichtshof nach dem Römischen Statut. Munich, Verlag H. C. Beck, 2003, p. 5 y ss.

7 Es una de las dos obligaciones, dentro del Estatuto, que requieren que el Estado legisle: la otra es la de tipificar como delitos de administración de justicia los que se cometan ante la Corte (cfr. el artículo 70 del Estatuto de la Corte Penal Internacional). 
celebrar sin dilación consultas con la Corte en caso de observar obstáculos o impedimentos para cumplir con alguna solicitud de cooperación.

Ahora bien, respecto de las situaciones que han sido remitidas a la Corte por el Consejo de Seguridad -Darfur (Sudán) y Libia-, la obligación de cooperar se ha ampliado a Estados no partes. Claramente, esta solicitud de cooperación no tiene como fuente la parte IX del Estatuto, sino, para ambas situaciones, en las resoluciones del Consejo de Seguridad en las cuales se efectúa la remisión a la Corte para que investigue ${ }^{8}$ y en las que se "decide" que los Estados involucrados en el conflicto deben cooperar y se "exhorta" a los demás a hacerlo también.

\section{La orden de detención contra Al Bashir}

El más bullado entre los casos en los cuales han dictado órdenes de detención, ciertamente es el que se sigue en contra de Omar Hassan Ahmad Al Bashir, Presidente en ejercicio de la República de Sudán. La Sala de Cuestiones Preliminares I de la Corte Penal Internacional ha dictado dos órdenes de detención en su contra ${ }^{9}$. La primera, de cuatro de marzo de $2009^{10}$, abarca crímenes de guerra ${ }^{11}$ y crímenes de lesa humanidad ${ }^{12}$; y la segunda, de doce de julio de 2010, por el crimen de genocidio ${ }^{13}$. Ambas órdenes de detención se justificaron haciendo una referencia copulativa a las tres causas que ameritan (cada una por separado) que se dicte una orden de arresto en lugar de una de comparecencia, conforme al artículo 58 del Estatuto de la Corte Penal Internacional. A saber, que la orden de detención (i) parece imprescindible para asegurar la comparecencia del imputado, (ii) para que no ponga en peligro la investigación en curso o (iii) para que no siga cometiendo los crímenes.

Este es sin duda un caso de particular relevancia, no sólo jurídica sino también simbólica para la Corte Penal Internacional. Y lo es por varias razones. Tal vez el principal motivo de este revuelo es el hecho de que el imputado en contra quien se dictó la orden de detención es un Jefe de Estado en pleno ejercicio del poder ${ }^{14}$. Si bien este hecho no contraría el Estatuto ${ }^{15}$, ni la política de la Fiscalía de la Corte Penal Internacional de centrar su quehacer en los más altos responsables ${ }^{16}$, lo cierto es que es una situación sin precedentes ${ }^{17}$.

8 Resolución № 1593 de 2005 y resolución № 1970 de 2011, respectivamente.

9 Sus textos están disponibles en http://www.icc-cpi.int/menus/icc/situations\%20and\%20cases/situations/situation\%20 icc\%200205/related\%20cases/icc02050109/icc02050109?lan=en-GB [citado el 19 de marzo de 2011].

$10 \mathrm{Al}$ respecto puede consultarse, ETCHEBERRY, Alfredo y CÁRDENAS, Claudia. La Corte Penal Internacional: abriendo caminos. Anuario de Derechos Humanos 2009 (5): p. 95-102; julio 2009.

11 Dirigir intencionalmente ataques contra una población civil como tal o contra civiles que no participen directamente en las hostilidades y saqueo (artículo 8 párrafo 2 letra e), numerales i) y v) del Estatuto de la Corte Penal Internacional)

12 Asesinato, exterminio, traslado forzoso de la población y tortura (artículo 7 párrafo 1 letras a), b) d) y f) del Estatuto de la Corte Penal Internacional).

13 Matanza, lesión grave a la integridad física o mental y sometimiento intencional a condiciones de existencia que hayan de acarrear la destrucción física (artículo 6 letras a), b) d) y c) del Estatuto de la Corte Penal Internacional).

14 Es Presidente de la República del Sudán desde su designación por el Consejo de Comando Revolucionario para la Salvación Nacional el 16 de octubre de 1993 y elegido como tal sucesivamente desde el 1 de abril de 1996.

15 Su artículo 27 párrafo 1 prescribe que: "El presente Estatuto será aplicable por igual a todos sin distinción alguna basada en el cargo oficial. En particular, el cargo oficial de una persona, sea Jefe de Estado o de Gobierno, miembro de un gobierno o parlamento, representante elegido o funcionario de gobierno, en ningún caso la eximirá de responsabilidad penal ni constituirá per se motivo para reducir la pena".

16 OFFICE OF THE PROSECUTOR. Paper on some policy issues before the Office of the Prosecutor. September 2003 Disponible en http://www.icc-cpi.int/NR/rdonlyres/1FA7C4C6-DE5F-42B7-8B25-60AA962ED8B6/143594/030905_Policy_Paper. pdf; [citado el 20 de marzo de 2011].

17 Hay precedentes sí de persecución de ex jefes de Estado, como es el caso de Charles Taylor ante la Corte Especial para Sierra Leona y Slobodan Milosevic ante el Tribunal Penal Internacional para la ex Yugoslavia. 
Otra razón de relevancia tanto jurídica, como simbólica, es la actitud displicente, cuando no abiertamente desafiante ${ }^{18}$, que ha asumido el imputado, quien ha hecho caso omiso de la orden y ha conseguido apoyo político en su región, favorecido sin duda por la circunstancia de que todas las investigaciones que ha abierto la Fiscalía de la Corte Penal Internacional conciernen a situaciones en Estados africanos ${ }^{19}$.

Tenemos entonces un imputado que, a diferencia de los demás que se sabe que tienen orden de detención pendiente, pero cuyo paradero se desconoce, tiene domicilio y actividades conocidas y públicas, en cuanto es jefe de un Estado que, aunque no es parte del Estatuto de la Corte Penal Internacional, igualmente está obligado a cooperar con el tribunal en virtud de una resolución del Consejo de Seguridad de Naciones Unidas. No obstante, él ha desconocido campantemente tal obligación, sin que hasta ahora el Consejo de Seguridad haya tomado medidas coercitivas para su cumplimiento (lo que no es de extrañar si se mira su práctica anterior respecto de los Tribunales ad hoc para la ex Yugoslavia y Ruanda). Al carecer la Corte de facultades para detenerlo, Al Bashir ha puesto abiertamente en jaque al sistema. De este modo se expone abiertamente la falta de imperio que caracteriza a todos los tribunales internacionales, pero que no deja de impactar por tratarse de un tribunal penal.

Siendo así, y comprendiendo la Corte que los mecanismos para forzar la cooperación de Sudán no dependen de ella, aparentemente la única posibilidad de concretar la detención, dejando de lado la de esperar un cambio de Gobierno en Sudán a uno de signo contrario, es que el presidente de Sudán sea detenido en algún viaje que realice fuera del país ${ }^{20}$. Por tanto, la Corte solicitó la cooperación de todos los Estados Partes de su Estatuto para ejecutar las órdenes de detención y entrega en contra de Omar Al Bashir. Sin duda, esta solicitud masiva de cooperación tiene también un componente simbólico, consistente en lograr que muchos Estados den una señal de desaprobación a la displicencia que ha mostrado Al Bashir hacia el tribunal.

Siendo Chile Estado Parte del Estatuto de la Corte Penal Internacional desde 2009, le fue remitida, como a los demás, la solicitud cumplir con la orden de detención y entrega contra Omar Al Bashir.

\section{La reacción del Estado chileno}

Ante la solicitud de cooperación, en concreto de detención y entrega, recibida el 19 de agosto de 2010 por el Embajador de Chile en los Países Bajos y remitida luego al Ministerio Público, éste reaccionó solicitando al presidente de la Corte Suprema la detención de Al Bashir, en un escrito ingresado el 9 de noviembre de 2010 (Rol N 8403-2010) ${ }^{21}$. Allí se explican los hechos, se reseñan las dos órdenes de detención emanadas de la Sala de Cuestiones Preliminares I y luego se hace mención del derecho chileno aplicable: el artículo 53 № 3 del Código Orgánico de Tribunales, que da al Presidente de la Corte Suprema competencia para conocer en primera instancia de las causas que deban juzgarse conforme al derecho internacional, y el artículo 19 $N^{\circ} 7$ letra c) de la Constitución ("nadie puede ser arrestado o detenido sino por orden de funcionario público expresamente facultado por la ley"). Se explica a continuación aquello en lo que

18 Que ha tenido una amplia cobertura de prensa, cfr. a saber http://www.elpais.com/articulo/internacional/Omar/Bashir/ burla/Haya/elpepiint/20090404elpepiint_8/Tes [citado el 20 de marzo de 2011].

19 Este punto ameritaría una discusión especial que no se incluye para no desviar la atención del tema principal.

20 Lo que ya ha hecho al menos en cinco ocasiones, viajando a Egipto, Eritrea, Libia, Qatar y Arabia Saudita, sin haber sido detenido.

21 No deja de llamar la atención la poco diplomática cobertura de prensa, que tituló "Fiscal nacional solicita a la Corte Suprema orden de detención contra dictador sudanés". Cfr. http://latercera.com/noticia/nacional/2010/11/680-3080909-fiscal-nacional-solicita-orden-de-detencion-contra-dictador-sudanes.shtmlm [citado el 19 de marzo de 2011]. 
-en general- consiste la solicitud de detención y entrega, a quien va dirigida y lo que pretende. Acto seguido, se explican las eventuales consecuencias de un incumplimiento de la solicitud de cooperación, tratándose, como sucede en este caso, de una situación remitida a la Corte Penal Internacional por el Consejo de Seguridad de Naciones Unidas. Finalmente se hace referencia a la Ley $N^{\circ} 20.357$, que tipifica en Chile los Crímenes de Genocidio, crímenes de lesa humanidad y crímenes de guerra, mismos que se le imputan al Al Bashirr2; y al Código Procesal Penal en sus artículos 20 bis, 443, 445 y 127.

El 25 de diciembre de 2010, el presidente de la Corte Suprema ordenó la detención de Omar Al Bashir en el evento de que ingrese en territorio nacional.

\section{Valoración de la reacción del Estado de Chile}

La recepción de la solicitud de cooperación puso a los operadores del sistema chileno en un escenario poco habitual. Si bien resulta indiscutible la obligación del Estado chileno de cooperar "plenamente con la Corte en relación con la investigación y el enjuiciamiento de crímenes de su competencia" (artículo 86 del Estatuto), las vías procesales concretas a seguir no están regladas. El Estado de Chile no ha cumplido una de las principales obligaciones de los Estados Partes en materia de cooperación: la de asegurar que en su derecho interno "existan procedimientos aplicables a todas las formas de cooperación especificadas" en la parte IX del Estatuto (artículo 88), entre las que se cuentan la solicitud de detención y entrega, a la que se refieren específicamente los artículos 58, 59, 89 y 91 del Estatuto de la Corte Penal Internacional ${ }^{23}$.

La solicitud de cooperación al Estado chileno para detener y entregar a Al Bashir tuvo importancia, sobre todo, como una prueba para probar el comportamiento de las autoridades chilenas ante una solicitud de cooperación por parte de la Corte Penal Internacional. Considerando estos hechos y el contexto en el que se enmarcan, resulta necesario sopesar la conducta del Estado, especialmente mirando el asunto desde la perspectiva del buen funcionamiento de la justicia penal internacional y el rol que le cabe a Chile en ello.

Por una parte, resulta positivo que los operadores del sistema chileno mostraran su voluntad de cooperar con la Corte Penal Internacional; en el caso del Ministerio Público, incluso sin contar con un procedimiento específico, examinando los mecanismos posibles para cumplir con la solicitud, y, por parte del Presidente de la Corte Suprema, dando lugar a lo solicitado, cumpliendo así las obligaciones contraídas por el Estado chileno.

Por otra, y sobre todo mirando al futuro, no puede pasarse por alto que si se requiriera cooperación en un caso más urgente, los tiempos de respuesta de nuestro sistema no permitirían que ésta fuera oportuna y eficaz: transcurrieron más de cuatro meses entre la solicitud de cooperación y la orden de cumplirla. Esta tardanza podría considerarse no tan grave si se piensa que existe el mecanismo de cooperación de la detención provisional a la que se refiere el artículo 92 del Estatuto de la Corte Penal Internacional, el cual contempla una mayor urgencia que la solicitud

22 Mutatis mutandis, cfr. CÁRDENAS ARAVENA, Claudia. La implementación de los crímenes de competencia de la Corte Penal Internacional en la ley N² 20.357. Revista de Derecho (Valdivia) vol. XXIII - № 2, pp. 23-44, diciembre 2010.

23 Artículo 89 del Estatuto de la Corte Penal Internacional párrafo 1: "La Corte podrá transmitir, junto con los antecedentes que la justifiquen de conformidad con el artículo 91, una solicitud de detención y entrega de una persona a todo Estado en cuyo territorio pueda hallarse y solicitará la cooperación de ese Estado. Los Estados Partes cumplirán las solicitudes de detención y entrega de conformidad con las disposiciones de la presente parte y el procedimiento establecido en su derecho interno". Cabe recordar la diferencia fundamental que el mismo Estatuto recalca entre "entrega" de una persona, que es lo que solicita la Corte Penal Internacional, y la "extradición", para la que normalmente los Estados prevén, que tiene como principal característica que se realiza de Estado a Estado, entre pares (artículo 102 del Estatuto de la Corte Penal Internacional). 
de detención y entrega. Con todo, al no existir una regulación procesal específica para esa forma de cooperación, caben serias dudas acerca de si la tramitación de una solicitud de detención provisional sería sustancialmente más rápida que lo que fue la solicitud de detención y entrega contra Omar Al Bashir.

Creo relevante hacer presente que, más allá de que contar con procedimientos específicos para las formas de cooperación previstas en el Estatuto de la Corte Penal Internacional sea una obligación jurídica específica para Chile como Estado Parte del Estatuto de la Corte Penal Internacional ${ }^{24}$, contar con esta normativa es de suma relevancia como muestra de buena fe en la participación en el sistema de jurisdicción penal internacional complementaria que establece el Estatuto de la Corte Penal Internacional. Esto implica prever y hacer lo necesario para dar curso, de manera oportuna, a las solicitudes de cooperación de las que depende el funcionamiento del sistema de justicia penal internacional del cual Chile es parte.

\section{Prospectivas}

En vista de estos acontecimientos, resta la esperanza que lo ocurrido a propósito de esta solicitud, y la muestra de voluntad de cooperar con la Corte Penal Internacional que han mostrado los agentes del Estado, sean el impulso que faltaba para legislar en la materia y podamos contar con una ley que, conforme a lo recomendado por la Asamblea de Estados Partes del Estatuto de la Corte Penal Internacional ${ }^{25}$, prevea autoridades punto de $\operatorname{contacto}^{26}$, funcionarios de enlace de cooperación y autoridades de ejecución, además de procedimientos a seguir para cada una de las formas de cooperación previstas en el Estatuto. Sería asimismo deseable que esas disposiciones procesales tengan en consideración las particularidades de la cooperación para con la Corte Penal Internacional respecto de la tradicional cooperación con otros Estados, propendiendo a establecer un régimen diferenciado y más expedito para las solicitudes de cooperación que provengan de la Corte $^{27}$. Lo anterior, habida cuenta de que su calidad de institución internacional -de la que Chile es Estado Parte- difiere de la de un Estado extranjero; e incluyendo la posibilidad, y en ciertos casos de obligatoriedad, de consultas a la Corte Penal Internacional, como se prevé en su Estatuto ${ }^{28}$. De este modo, el Estado cumpliría no solamente con la obligación específica y literal del artículo 88, sino también con la más general de cumplir de buena fe los tratados que ha ratificado en ejercicio de su soberanía.

24 CIAMPI, Analisa. The obligation to cooperate. En: CASSESE, Antonio et al. The Rome. Statute of the International Criminal Court: A Commentary. Oxford, Oxford University Press, 2002, p. 75 y ss.; SCHABAS, William. The International Criminal Court. A commentary on the Rome Statute. Oxford, Oxford University Press, 2010, p. 987.

25 ASAMBLEA DE ESTADOS PARTES, Informe de la Mesa sobre la cooperación, sexto período de sesiones. Nueva Cork, 30 de noviembre a 14 de diciembre de 2007, párrafo 3. Cfr. http://www.icc-cpi.int/iccdocs/asp_docs/library/asp/ICCASP-6-21_Spanish.pdf, [visitado el 19 de marzo de 2011]. Cfr. también el párrafo 74: "Los Estados Partes deberían asegurar la existencia de legislación de aplicación adecuada y de acuerdos complementarios para hacer posible la cooperación y cerciorarse de que se han establecido las estructuras y procedimientos adecuados para que esa cooperación discurra plácidamente. En pocas palabras, los Estados Partes deberían reforzar un entorno favorable mediante la creación de un marco universal de cooperación".

26 Especie de autoridad central que recibe todas las solicitudes de cooperación y deriva luego internamente a la autoridad interna que corresponda para que se ejecute lo pertinente según los procedimientos internos del Estado.

27 BASSIOUNI, Cherif. The Legislative History of the International Criminal Court. Introduction, Analysis and Integrated Text. Volumen 1, Nueva York, Transnational Publishers, 2005, p. 178; QUESADA ALCALÁ, Carmen. La Corte Penal Internacional y la soberanía estatal. Valencia, Tirant lo Blanch, 2005, p. 403.

28 El Estatuto de la Corte Penal Internacional prevé consultas en varios artículos de su parte IX (89, 91, 93, 96, 97 y 99). Entre las disposiciones sobre consultas, la más relevante es la del artículo 97, que establece una obligación de consultar "si considera que la solicitud le plantea problemas que puedan obstaculizar o impedir su incumplimiento". La finalidad de esta obligación pareciera ser abordar en conjunto eventuales obstáculos evitando la escalada de conflictos y haciendo en definitiva más expedito el cumplimiento de las solicitudes de cooperación. Cfr. MEISSNER, Jörg. Die Zusammenarbeit mit dem Internationalen Strafrerichtshof nach dem Römischen Statut. Munich, Verlag H. C. Beck, 2003, p. 46. 